\title{
A Companhia de Jesus em São Luís do Maranhão: Considerações sobre pintura e talha na Catedral da Sé
}

\author{
Society of Jesus in São Luís of Maranhão: \\ Considerations about painting and carving in Sé Cathedral \\ Regiane Aparecida Caire Silva* y Marília Martha França Sousa**
}

Resumo: Este estudo aponta a importância da Companhia de Jesus em São Luís do Maranhão, sobretudo no que se refere ao contexto das práticas artísticas jesuíticas encontradas na Catedral da Sé e sua preservação. Para efetuar esta tarefa, relata-se a contribuição dos inacianos a partir do século XVII na edificação do Colégio e da Igreja da N. S. da Luz e o percurso até se transformarem no Palácio Episcopal e Catedral da Sé. Os edifícios sofreram intervenções significativas e drásticas, principalmente as realizadas para as comemorações do Centenário da Independência do Brasil, em 1922. A pesquisa mostra que apenas o retábulo do séc. XVII sobreviveu até a atualidade, e prova que, ainda no início do século XX, existia uma pintura realizada pelos jesuítas no forro da capela-mor considerada "magnífica", entretanto, destruída com as inúmeras reformas do templo.

Palavras-chave: Companhia de Jesus; Igreja Nossa Senhora da Luz; Colégio da Luz; Pintura Jesuítica; Talha jesuítica

Abstract: This study points out the importance of Companhia de Jesus in São Luís do Maranhão, specially regarding the context of the jesuític artistic practices found in Sé's

\footnotetext{
* Doutora em História da Ciência pela Pontifícia Universidade Católica de São Paulo - PUC-SP - Brasil, Coordenadora e professora titular do Curso de Licenciatura em Artes Visuais, professora da Pós Graduação do Mestrado Profissional em Artes da Universidade Federal do Maranhão - UFMA - Brasil E-mail: regiane.caire@ufma.br. Brasil.

** Graduada em Licenciatura em Educação Artística pela Universidade Federal do Maranhão - UFMA.Brasil. Atualmente é professora substituta do Curso de Licenciatura em Artes Visuais da UFMA e possui pesquisas na área de Educação Patrimonial. E-mail: mariliafrancama@outlook.com. Brasil.
}

31 Regiane A. Caire Silva y Marília M. França Sousa. A C de J em São Luís... 31-50. 
Cathedral and its preservation. In order to accomplish this task, it's described the contribution of igatians as from the XVII century in the building of the School and the N.S. da Luz Church and the way until they became the Episcopal Palace and Sé's Cathedral. The buldings have suffered significative and drastic interventions, specially the ones made for Brazil's Independence Centenary in 1922. The research shows that only the altarpiece of the XVII century survived so far and proves that, still in the beginning of the XX century, there was a painting made by the jesuits on the lining of the chancel considered "magnificent", that was, however, destroyed with the numberless reformations of the temple.

Keywords: Society of Jesus; Nossa Senhora da Luz Church; Colégio da Luz; Jesuit Painting; Jesuit Carving

Recibido: 11 de julio de 2015

Evaluado: 11 de octubre de 2015 


\section{A formação da cidade de São Luís e a chegada da Companhia de Jesus}

A arquitetura religiosa no Maranhão possui peculiaridades específicas, tendo a Ordem da Companhia de Jesus exercido grande influência no início das construções que emergiram junto ao primeiro núcleo da cidade na metade do século XVII.

No século XVI algumas regiões no nordeste já apresentavam centros urbanos mais estruturados, como Bahia e Pernambuco, o mesmo não ocorreu com a região norte onde a demarcação do território ainda estava incipiente, o que atraia e facilitava a presença de corsários - principalmente holandeses e franceses - praticando o escambo com os índios.

Dentro deste cenário encontrava-se o Maranhão, dividido pelos portugueses em duas capitanias hereditárias pelo Tratado de Tordesilhas (1534). Apesar do objetivo de ocupação e colonização pela coroa portuguesa - com várias tentativas fracassadas foram os franceses com Daniel de La Touche que fundaram a cidade em 1612. De início construíram o forte de Saint Louis com a ajuda dos índios para defesa e alteraram o nome da ilha de Upaon Açu para São Luís, em homenagem ao rei Luís XIII da França. A ideia da França Equinocial, cobiçada desde 1604 por Henrique IV, parecia alcançada com Daniel de La Touche, senhor de La Ravardière.

No curto período de três anos que permaneceram como colonos os franceses obtiveram relação amistosa com os índios Tupinambás e foram auxiliados nas questões religiosas pelos padres franciscanos capuchinhos, no entanto, sob pressão da Espanha, os franceses foram expulsos pelos portugueses em 1615 . $^{2}$ Nessa época, Portugal estava sobre o domínio da Coroa espanhola, que preocupada em resguardar suas minas de ouro e prata no Peru, forçou Portugal a colonizar efetivamente o Maranhão. Alegando que a proximidade dos franceses poderia facilitar, devido ao traçado dos rios, a exploração das minas espanholas por uma rota partindo do Maranhão, Pará ou Amazonas devido a extensa bacia hidrográfica da região. ${ }^{3}$

Reconquistada a província em 1615 pelos portugueses na Batalha de Guaxenduba, sob o comando de Jerônimo de Albuquerque, a colônia lusitana é consolidada e "com uma forma mais estável de ocupação, surgem, no mesmo sítio em que aportaram os franceses, as primeiras manifestações lusitanas de caráter urbano" 4 .

Somando com os primeiros colonos vieram ordens religiosas como os Carmelitas, Franciscanos, Mercedários, Irmandade do Rosário dos Pretos e os Jesuítas que já estavam no continente americano desde 1549 atuando da Amazônia até o Rio da Prata edificando colégios e templos 5 .

No recém território conquistado criou-se em 1621 o Estado do Maranhão e Grão Pará, com o intuito de proteger o que compunha a única rota de entrada na Amazônia, assim, sua administração tornou-se independente do restante do Estado do Brasil.

\footnotetext{
${ }^{1}$ Bettendorff, J. F., 2010: LXVIII.

${ }^{2}$ Sobre a colonização francesa ler os religiosos Claude d'Abbeville que esteve no Maranhão nos primeiros quatro meses e Yves d'Évreux que permaneceu por volta de dois anos e escreverem respectivamente: História da Missão dos Padres Capuchinos na Ilha do Maranhão e Ação e Presença dos Portugueses na costa norte do Brasil no séc. XVII ambos da Editora do Senado Federal, Brasília.

${ }^{3}$ Brito, Stella. R.S. et al, 2000: 15.

${ }^{4}$ Silva Filho, O. P., 1998: 17.

${ }^{5}$ Ibíd.: 139.
}

33 Regiane A. Caire Silva y Marília M. França Sousa. A C de J em São Luís... 31-50. 
A separação foi efetivada, completamente, em 1626, ficando essa região diretamente subordinada a Portugal.

Mesmo com a ocupação portuguesa existiam problemas, como a dificuldade de encontrar colonos para assentamentos, mão de obra escrava escassa e agricultura ainda bem modesta, com esse quadro, a recém fundada colônia foi novamente invadida em 1641, agora, pelos holandeses. De maneira contrária aos franceses, os flamengos destruíram a pequena cidade e, segundo Olavo Pereira, não deixaram nenhum imóvel de sua autoria reconhecido até os nossos dias; com reforço português, foram expulsos em $1644 .^{6}$

Após as invasões os habitantes do Maranhão procuraram administrar e reestruturar a economia que estava alicerçada, principalmente, na mão de obra indígena, os quais detinham conhecimento e extração dos produtos naturais que eram enviados para Portugal. Assim, quem detivesse a confiança e domínio dos silvícolas teriam o controle da economia, disputa entre governo e ordens religiosas, no caso mais específico, com a Companhia de Jesus árdua defensora da liberdade dos indígenas.

A Companhia de Jesus chegou a São Luís em 1615, após expulsão dos franceses na expedição do português Jerônimo de Albuquerque. Anterior a esta data, em 1607, houve tentativa da entrada dos jesuítas no Maranhão, "D. Diogo Botelho governadorgeral do Brasil decide colocar missionários a frente da empresa de conquistas do Maranhão destacando Francisco Pinto e Luís Figueira." 7 A missão foi atacada pelos índios no caminho, o padre Francisco Pinto morreu e o padre Luís Figueira conseguiu retornar para a Paraíba.

Segundo D. Francisco de Paula e $\operatorname{Silva}^{8}$ o padre Moraes está correto na informação sobre os primeiros jesuítas que vieram para São Luís:

com a esquadra de Alexandre de Moura vieram não os Padres Amodei e Figueira, Lopo do Couto e um irmão leigo; mas, sim, os Padres Manuel Gomes e Diogo Nunes, ambos versadíssimos na língua brazileira, os quaes, depois da retirada dos francezes ficaram os únicos Religiosos na ilha, visto como voltaram para Pernambuco os dois Religiosos Franciscanos, que tinham vindo na esquadra de Jeronymo d'Albuquerque como capelães dos soldados. E aos Jesuítas que ficaram foi feita a doação do hospício e capela dos Capuchinhos francezes, pelo Capitão-mór, em nome de sua majestade. ${ }^{9}$

D. Francisco coloca que os Jesuítas fundaram sua primeira Missão em Uçagoába, hoje um bairro chamado Vinhais, dedicando-se aos indígenas e portugueses no apostolado. E que os padres inacianos Manuel Gomes e Diogo Nunes chegaram a São Luís em 1615 saindo de Recife por oceano sendo recebidos pelos Capuchinhos franceses, trabalharam sozinhos até 1619 ano que voltaram para Madri. Somente em 1622, vieram os padres Luiz Figueira e Benedicto Amodei e em 1624 chegou o padre Lopo Couto com um irmão coadjutor.

\footnotetext{
${ }^{6}$ Para maiores informações sobre a invasão e expulsão holandesa ver: Bettendorff, Filipe J.,2010: 69-72.

${ }^{7}$ Brito, Stella R.S. et al., 2000: 25.

${ }^{8}$ Paula e Silva, F., 1922: 18.

${ }^{9}$ Cita Moraes, Padre José de. (s/d), História da Companhia de Jesus na extinta Província do Pará e Maranhão: 110-111.
}

34 Regiane A. Caire Silva y Marília M. França Sousa. A C de J em São Luís... 31-50. 
Com estes missionários e alguns outros, sucessivamente mandados para esta missão, continuou a Companhia no Maranhão até 1649, data em que os índios Tapajoz, armados, mataram no Rio Itapicuru os Padres Francisco Pires, Manuel Moniz e João d'Almeida, coadjutor. Ficou sem religiosos dessa Ordem o Maranhão até 1652, quando vieram os Padres Francisco Velloso e João de Souto-Maior com mais 8, mandados adeante pelo Padre Vieira, que de Lisboa vinha como Superior da Missão. A 17 de janeiro de 1652 chegava o grande Jesuíta com mais 3 Padres. Dali em deante sempre continuaram no Maranhão, embora expulsos pelo povo em 1661 e em $1684 .^{10}$

A relação da Ordem dos Jesuítas com o governo local e com os colonos portugueses no Maranhão não foi tranquila. Nessa conjuntura chega em 1653, a S. Luís, o padre Antônio Vieira famoso por suas pregações em defesa dos índios. Depois de cumprir com suas atividades, não só de catequese como também os interesses materiais da Ordem, retorna a Lisboa e concretiza textos legais em 14 de abril de 1655, cujo teor interfere diretamente em questões políticas e econômicas, relacionados ao poder e administração dos índios pela Companhia, o que desagradou muitas pessoas.

Que as aldeias e os índios de todo o Estado sejam governados e estejam sob a disciplina dos religiosos da Companhia de Jesus; e que o padre Antônio Vieira, como superior de todos, determine as missões, ordene as entradas ao sertão e disponha os índios convertidos à fé pelos lugares que julgar mais conveniente. ${ }^{11}$

Com tanto poder adquirido com a lei houve pressão para a prisão e expulsão do padre Antônio Viera e seus companheiros, assim, em 8 de setembro de 1661 foram enviados para Lisboa e, a partir de então, o padre Vieira nunca mais pisou em terras maranhenses. A pesar de sua lei de 1655 ter sido contestada em 1663, tirando o poder dos jesuítas e excluindo o padre Vieira de qualquer ingerência religiosa no governo temporal dos índios, em 1680 é promulgada pelo rei de Portugal a lei que "abolia de modo completo a escravidão dos indígenas no Brasil"12, porém, na prática, não foi assim que ocorreu.

O fato dos inacianos defenderem os índios contra os maus tratos e lutarem pela sua liberdade geraram opositores e manifestantes sempre a favor da expulsão da Companhia de Jesus. Uma prova desta insatisfação foi a revolta de Beckman em 1684, a qual os colonos criticavam a ação dos jesuítas na administração da Companhia de Comércio que impedia a escravização dos índios, bem como, algumas ordens religiosas apoiaram a revolta por acharem que os inacianos detinham muito poder. $\mathrm{O}$ resultado gerou o fechamento no ano seguinte da Companhia Geral do Comércio. ${ }^{13}$ Em 1759 a Companhia de Jesus foi expulsa do Brasil tendo seus bens confiscados.

Os assentamos dos missionários jesuítas em São Luís tiveram relevante importância na construção das vilas, na educação, na catequese dos índios e colonos, como também na construção do Colégio e Igreja da Nossa Senhora da Luz - projeto e desenho do Padre Jesuíta João Filipe Bettendorff.

\footnotetext{
${ }^{10}$ Paula e Silva, F.,1922: 25.

${ }^{11}$ Bettendorff, J. F., 2010: XLIII - XLIV.

12 Ibíd.: L.

${ }^{13}$ Brito, Stella.R.S., 2000: 36.
}

35 Regiane A. Caire Silva y Marília M. França Sousa. A C de J em São Luís... 31-50. 


\section{Catedral da Sé}

A igreja Nossa Senhora da Vitória foi a primeira matriz de São Luís, erguida em 1621 e estava localizada onde era o antigo Hotel Central ${ }^{14}$ onde, atualmente, funciona o Palácio do Comércio. Não encontramos dados concretos que indiquem a data e nem as circunstâncias em que este templo foi destruído.

$\mathrm{O}$ nome da igreja está relacionado à vitória dos portugueses em relação aos franceses na Batalha de Guaxenduba, a qual foi concebida pela ajuda direta de Nossa Senhora que, segundo relatos, lhes conferiu a vitória na batalha. A respeito deste episódio o padre Bettendorff relata que o "Céu fez justiça à Portugal contra a injusta agressão com que a França acometia o Maranhão, fez vazasse a maré mais do costumado deixando as canoas dos franceses em seco". Além do recuo da maré, descreve uma senhora - a própria Virgem Nossa Senhora - que aparece no meio da batalha animando-os a lutar bravamente, distribuindo pólvora e balas, "de trezentos franceses não sobraram mais de cinquenta com vida ficando só três mortos da parte dos portugueses por milagre manifesto". ${ }^{15}$

Em 1626, coube ao padre jesuíta Luís Figueira a missão de, além da fundação do Colégio da Luz, construir uma nova igreja para a Ordem. "Em 1626, o Pe. Luís Figueira construiu também a primeira capela do Colégio dedicada a Nossa Senhora da Luz". ${ }^{16}$ Observa-se que no ano de sua construção a igreja dos jesuítas ainda não se configurava como Catedral como seria posteriormente, mas sim, como uma pequena capela construída de pedra e cal, constituída de capela-mor, nave e sacristia. A igreja erguida pelo padre Luís Figueira não resistiu ao tempo, vários pedidos para reformas foram solicitados, no entanto, não atendidos, o que veio ocasionar sua demolição em 1693.

Em 1690 estando à frente da Missão no Maranhão o padre João Filipe Bettendorff realiza o início das obras para a construção da nova igreja dos jesuítas, localizada próximo a ala do corredor sul do Colégio, com inauguração solene em 1699. O próprio padre realizou o "debuxo" para a fachada e retábulo do altar-mor. Em suas Crônicas Bettendorff apresenta detalhes sobre as obras da nova igreja:

Muitos anos haviam que me acompanhavam grandes desejos de fabricar um belo templo novo à Virgem Senhora Nossa da Luz, padroeira do Colégio e de toda à Missão do Maranhão, para esse fim, sendo Superior da primeira vez, mandei ajuntar, pedras, cal, madeira em grande quantidade [...], deputei também os índios Guajajaras da aldeia de Mareú, que sua Majestade tinha concedido ao Colégio. ${ }^{17}$

Características estilísticas que indiquem a fachada da igreja nesse período são escassas, porém, a obra realizada pelo padre em colaboração com os índios nos dá indícios de ser esta uma autêntica construção do período colonial baseada no risco dos jesuítas. A igreja Nossa Senhora da Luz foi elevada a Sé Catedral após a última expulsão da Companhia de Jesus no Maranhão, ocorrida no ano de 1759. A matriz estava em ruínas e com a desapropriação por decreto dos imóveis dos jesuítas a igreja dos inacianos passa ser a Catedral da Sé, com mudança de seu nome para Nossa Senhora da Vitória.

\footnotetext{
${ }^{14}$ Pacheco, D. F. C., 1969: 11.

${ }^{15}$ Bettendorff, J. F., 2010, Livro I, Cap. III: 9.

${ }^{16}$ Pacheco, D. F. C., 1969:12.

${ }^{17}$ Bettendorff, J. F., 2010: 501-502.
}

36 Regiane A. Caire Silva y Marília M. França Sousa. A C de J em São Luís... 31-50. 
Há discordância entre alguns estudiosos da história do Maranhão acerca da data exata de quando a Igreja da Luz foi elevada a condição de Sé. Para o historiador Carlos de Lima, "em 17 de agosto de 1762 fez-se a mudança da antiga Sé para a atual, a catedral do Maranhão, sob o orago de Nossa Senhora da Vitória"; ${ }^{18}$ já para a historiadora Kátia Bogéa, no ano de 1768 a Igreja de Nossa Senhora da Luz passa por reformas significativas, pois visava adaptá-la a Sé Catedral; ${ }^{19}$ outra data aparece no texto de Dom Francisco de Paula e Silva que relata ter sido em 11 de junho de 1761 através de alvará régio designando a igreja de Nossa Senhora da Luz para Catedral e o Colégio dos Jesuítas para o Palácio dos Bispos. ${ }^{20}$

\section{O Colégio de Nossa Senhora da Luz e o retábulo produzido na oficina de entalhe.}

Com a chegada das primeiras missões da Companhia de Jesus em terras brasileiras, no ano de 1549, fez-se necessário para o estabelecimento da Ordem a construção de escolas, igrejas, seminários, colégios e fazendas para aldeamentos.

No Maranhão o Colégio de Nossa Senhora da Luz foi instituído pelo padre Luís Figueira entre os anos de 1626 e 1627. "Foi o Pe. Luís Figueira o fundador do colégio dos jesuítas e quem organizou o governo, dito espiritual das aldeias." ${ }^{21}$ Sabe-se ainda através do autor Carlos de Lima que o Colégio neste período destinava-se a ensinar letras aos filhos dos portugueses, e que tiveram suas atividades suspensas com a morte dos padres no massacre ocorrido na cidade de Itapecuru em $1649^{22}$.

O Colégio de Nossa Senhora da Luz passou três anos sem exercer nenhum tipo de atividade em decorrência da morte dos padres. Apenas em 1652, com a chegada da missão trazida pelos padres Francisco Veloso e João de Souto Maior, e em 1653 com o padre Antônio Vieira, o Colégio foi aos poucos reconstruído e retornando as suas atividades.

No ínterim entre o ano da fundação do Colégio até a morte dos padres não há indícios da existência de oficinas. Porém, no período em que o padre Antônio Vieira esteve a frente da Missão no Maranhão, entre os anos de 1653 e 1661, surgem os primeiros relatos do que viria a ser oficialmente a oficina de escultura, pintura e entalhe do Colégio da Luz. "Por volta de 1659, o padre Antônio Vieira deu início a uma série de reformas no Colégio de Nossa Senhora da Luz. As descrições dessas reformas citam, pela primeira vez, as oficinas: ficando as oficinas em quadra para a banda do mar... ${ }^{23}$.

Após o estabelecimento da Ordem pelo padre Antônio Vieira e com as oficinas sendo construídas nas dependências do Colégio, houve a necessidade de trazer os primeiros mestres jesuítas artífices que viriam trabalhar na construção e ornamentação das igrejas. Estes trouxeram habilidades e técnicas aprendidas no Reino que iriam ser aglutinadas às habilidades já presentes nos silvícolas que habitavam no Maranhão. A

\footnotetext{
${ }^{18}$ Lima, C.; Meireles, M.; Bogéa, K. S., 2002: 62.

${ }^{19}$ Bogéa, K. S.; Ribeiro, E. S.; Brito, Stella, R. S., 2008: 82.

${ }^{20}$ Paula e Silva, F.,1922: 135.

${ }^{21}$ Lima, C.; Meireles, M.; Bogéa, K. S., 2002: 20.

${ }^{22}$ Ibid.: 22 .

${ }^{23}$ Bógea, K.; Brito, S.; Ribeiro, E., 2002: 26.
}

37 Regiane A. Caire Silva y Marília M. França Sousa. A C de J em São Luís... 31-50. 
necessidade de artífices para as oficinas ocorreu não só no Maranhão, apesar de tardiamente, mas em vários lugares do país, como comenta Serafim Leite:

Isto nos começos e dentro do Estado do Brasil. E o mesmo sucede-se no do Maranhão, quase um século depois, ao proceder-se à sua evangelização, em que se sentia a mesma necessidade de artífices. Vieira pedia e insistia em 1660, com o P. Geral, que enviasse 'irmãos coadjutores oficiais, principalmente pintores, alfaiates, sapateiros, carpinteiros, pedreiros ${ }^{24}$.

Com o término dos trabalhos realizados pelo padre Antônio Vieira e a Missão nas mãos do padre Bettendorff ${ }^{25}$, o Colégio de Nossa Senhora da Luz e, consequentemente suas oficinas, atingem um elevado nível de produção artística e intelectual, chegando a ser comparado aos Colégios de Coimbra e da Bahia:

O Colégio da Luz desenvolveu após seu ensino, ao ponto de equiparar-se ao de Coimbra e ao da Bahia, conferindo graus, em letras, ciências, artes, filosofia e teologia. Alunos gratuitos, sem nenhuma distinção racial ou de classe. Suas oficinas produziram apreciáveis obras de pintura e estatuária. Suas obras de talha ainda ornam a nossa Catedral. ${ }^{26}$

Durante a permanência do padre Filipe Bettendorff frente à Missão do Colégio, este empreendeu o que viria a ser uma das maiores reformas na igreja de Nossa Senhora da Luz - anexo às dependências do Colégio. Durante o período da reforma, entre os anos de 1690 e 1699, esteve à frente das oficinas e realizou junto aos outros mestres artífices e indígenas trabalhos de estatuária e talha, com destaque para a construção do retábulo do altar-mor. Para as atividades que seriam realizadas na reforma da Igreja da Luz e para construção do retábulo solicitou que chegassem ao Maranhão em

1688, no dia 20 de Outubro, dia das 11 mil virgens, chegaram: Antônio Gonçalves e Diogo da Costa, padres, Manoel Rodrigues, Manoel da Silva e João Geraldo Ribeiro, irmãos, vindos de Pernambuco; mais os padres João Ângelo e Francisco Soares e os irmãos Tomás Carneiro, Tomás de Couto, José da Fonseca, Cláudio Gomes, Miguel e José Carvalho. Nesta mesma comitiva veio o marceneiro Francisco. ${ }^{27}$

À frente dos trabalhos na oficina, Filipe Bettendorff exercia o ofício de desenhista e pintor tendo realizado por suas próprias mãos o "debuxo" para o retábulo da Igreja da Luz. Com sua equipe já formada inicia os trabalhos de entalhe do retábulo do altar-mor, elaborado entre os anos de 1693 a 1699. Contou com a participação do entalhador Manoel Mansos vindo de Portugal e outros mestres de ofícios, em suas Crônicas nos dá detalhes sobre a construção do retábulo:

[...], é feito um retábulo de cedro que podia aparecer com as melhores igrejas da cidade, dando ela a traça e sendo os entalhadores Francisco, filho de Alonso, feitor da ilha, e Mandú com Miguel, carapinas da fazenda. Tinha eu posto Francisco com Diogo de Souza, entalhador [...], e lhe tinha posto em mão a pena para aprender a debuxar, tendo visto nele grande habilidade para obras de

\footnotetext{
${ }^{24}$ Leite, S., 1953: 20.

${ }^{25}$ O padre João Filipe Bettendorff era natural de Luxemburgo, chegou ao Maranhão no ano de 1661. Viveu entre o Maranhão e o Pará durante trinta e sete anos.

${ }^{26}$ Pacheco, D. F. C., 1969: 12.

${ }^{27}$ Lima, C.; Meireles, M.; Bogéa, K. S., 2002: 52.
}

38 Regiane A. Caire Silva y Marília M. França Sousa. A C de J em São Luís... 31-50. 
entalhador e para sair destro de tudo o tinha posto com Manuel Mansos, entalhador do Reino. ${ }^{28}$

Filipe Bettendorff, os mestres artífices jesuítas e os indígenas que aqui habitavam, nos deixaram como herança a expressão máxima de uma época traduzida em forma de arte, transformaram madeira com o uso da talha em linguagem.

O Retábulo do altar-mor da Igreja de Nossa Senhora da Vitória possui características singulares. Para o pesquisador Benedito Lima de Toledo, ${ }^{29}$ em seus estudos sobre a morfologia dos retábulos, o exemplar presente na Catedral da Sé de São Luís está classificado num estilo denominado "estilo nacional português", que caracteriza-se por:

Composições que lembram as portadas românicas das capelas existentes particularmente no norte do país. De cada lado, colunas de fuste espiralado tendo como arremate superior arcos concêntricos tratados da mesma forma. Ao centro uma tribuna destinada a receber a imagem do santo. É a composição que vemos, por exemplo, na igreja matriz de Bravães."30

O conjunto que configura o retábulo da Igreja da Vitória revela muitas características presentes neste estilo, a saber: conjunto com oito colunas ricamente ornamentadas com motivos fitomórficos - cachos de uvas, folhas de palma e acanto; arcos concêntricos, um sobreposto ao outro, ambos rendilhados, com a mesma ornamentação - folhas de parreiras e pombos da paz; colunas com dinamismo alcançado pela forma helicoidal que possuem.

Segundo Benedito Lima, este estilo pode ser encontrado em diversas igrejas do Brasil, em que destaca a importância do exemplar da Igreja da Vitória: "no Brasil, esse tipo de retábulo conheceu grande difusão. Vamos encontrá-lo em todo o país. Em São Luís do Maranhão no altar-mor da igreja do colégio dos jesuítas, há um exemplar monumental talvez o melhor do gênero"31.

Este rico trabalho realizado pela oficina de entalhe do Colégio dos jesuítas no Maranhão revela muito mais do que esta breve descrição, uma vez que o tema em questão é apresentar as intervenções reversíveis e irreversíveis realizadas na obra que comprometeram a sua originalidade.

Para reforçar ainda mais a importância dada ao retábulo, cita-se o arquiteto Lucio Costa diretor da Divisão de Estudos e Tombamentos do DPHAN ${ }^{32}$. No processo de tombamento em 1954, destaca apenas o retábulo como elemento principal a ser reconhecido, e não a Catedral de Nossa Senhora da Vitória no seu todo, já bem comprometida com as intervenções.

A edificação não apresenta interesse suficiente para o tombamento. Justifica-se, entretanto, a inclusão, no Livro de Tombo de Belas Artes, o retábulo do altar-

\footnotetext{
${ }^{28}$ Bettendorff, J. F., 2010: 507.

${ }^{29}$ Benedito Lima de Toledo é arquiteto e historiador. Professor da Faculdade de Arquitetura e Urbanismo da Universidade de São Paulo - FAU.

${ }^{30}$ Toledo, B. L. de., 1983: 177.

${ }^{31}$ Toledo, B. L. de., 1983:180.

${ }^{32}$ Diretoria do Patrimônio Histórico e Artístico Nacional, sigla utilizada de 1946 a 1970.
}

39 Regiane A. Caire Silva y Marília M. França Sousa. A C de J em São Luís... 31-50. 
mor, peça jesuítica que deve provir de fins do século XVII ou do primeiro quartel do século XVIII, embora o camarim date do século XIX. ${ }^{33}$

\section{Intervenções}

Entre o final do século XIX início do século XX a cidade de São Luís passa por um intenso processo de modernização. Construções de novas pontes para ligar o centro histórico aos novos espaços que emergem na cidade, verticalização acelerada, alargamento de ruas, fazem parte das características apresentadas na "nova São Luís".

A necessidade de atualização alia-se a uma nova adequação de algumas construções históricas, incluindo casarões, prédios públicos e igrejas do período colonial. O caso que chama atenção do nível empregado pelas intervenções foi observado na Igreja de Nossa Senhora da Vitória/Catedral da Sé e na fachada do Palácio Episcopal localizado ao lado do templo, hoje, o prédio abriga o Museu de Arte Sacra.

Encontra-se no arquivo digital da Biblioteca Nacional de Portugal uma litografia de 1856 (Fig.1), que mostra a antiga igreja dos jesuítas Nossa Senhora da Luz sob o orago de Igreja Nossa Senhora da Vitória, em termos de registro iconográfico este foi o mais antigo constatado nesta pesquisa.

Pode-se supor ser a litografia um trabalho de registro da celebração de entrega da igreja aos fiéis após o término de prováveis reformas, pois no ano de 1854 foi realizada solenidade de entrega do templo que havia sido atingido por descargas elétricas:

O majestoso templo consagrado a Nossa Senhora da Vitória, que serve de Catedral, e fora ereto pelos jesuítas, tinha sido muito danificado por um raio, e achava-se em reparos, quando chegou o Exm $^{\circ}$ Prelado à diocese; um outro raio ainda no dia 20 de Abril desse ano veio completar a obra da destruição! [...] e o templo restaurado foi aberto, e havendo-o benzido solenemente, já pode nele celebrar as solenidades da quaresma de $1854 .{ }^{34}$

\footnotetext{
${ }^{33}$ Costa, L., 2004: 142.

${ }^{34}$ Jornal O Eclesiástico, de 04 de Junho de 1862, ano X, nº 233.
} 


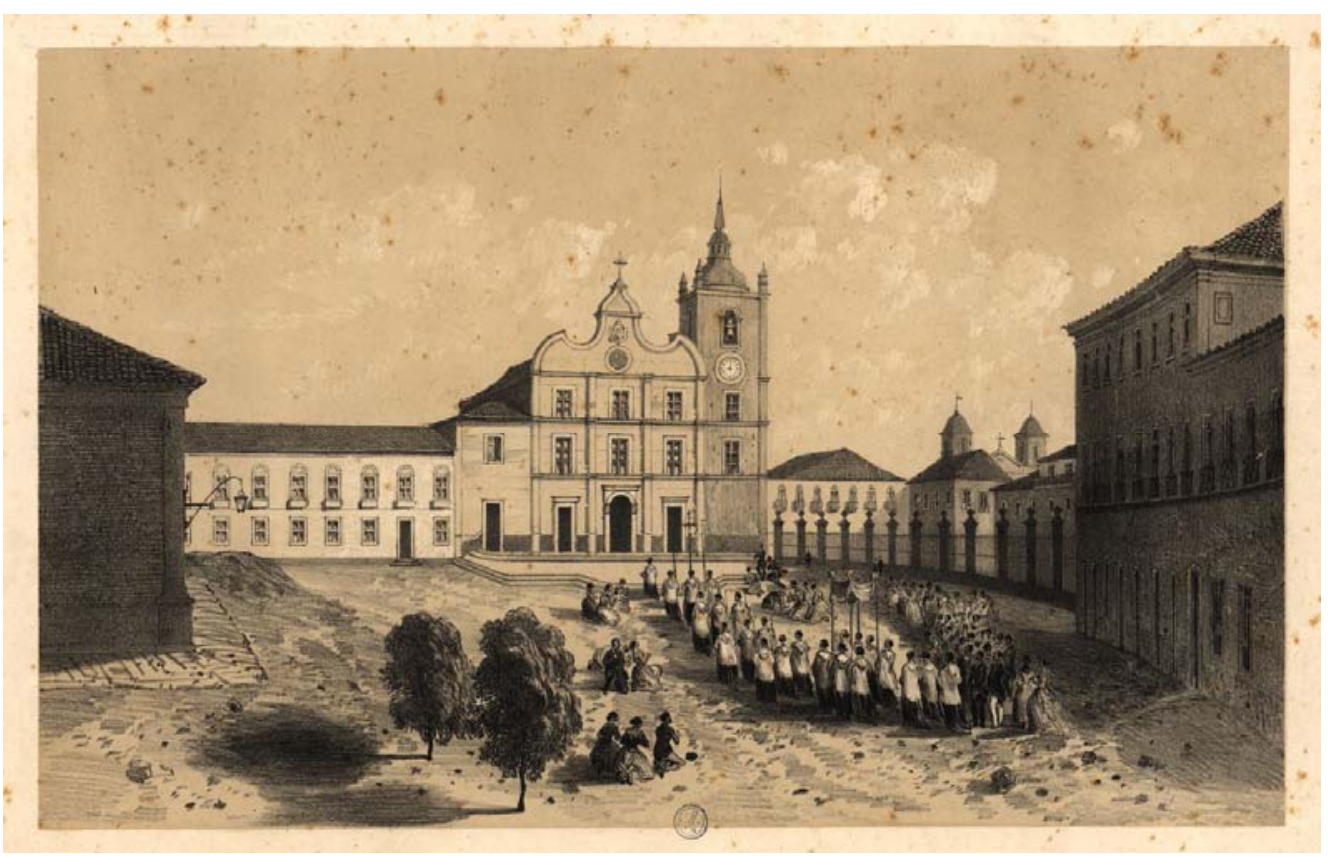

Fig. 1 Catedral de São Luís do Maranhão Litografia de 1856, de Friederich Hagerdorn . Impressa em Paris por Bernard Lemercier. Fonte: Arquivo Digital da Biblioteca de Portugal ${ }^{35}$

$\mathrm{Na}$ procura de imagens antigas da Catedral da Sé e do Palácio Episcopal encontramos registros realizados pelo fotografo paraense Gaudêncio Cunha, entre os quais fazem parte do Álbum do Maranhão de $1908^{36}$.

Este álbum composto por 211 fotografias originais é um objeto único, resultado do trabalho de Gaudêncio que viveu em São Luis por volta de trinta anos.

Comparando as imagens da litografia de 1856 com a fotografia de 1908, nota-se pouca alteração na fachada (Fig.2) do templo religioso.

São 52 anos de distância entre as duas imagens. Pode-se observar a presença do Brasão da Coroa Imperial Portuguesa no frontispício do templo da litografia, possivelmente no lugar do famoso Brasão da Ordem da Companhia de Jesus retirado após a última expulsão ${ }^{37}$. Já na foto de Gaudêncio não aparece sobre o óculo, devido, com certeza, a Proclamação da República do Brasil que ocorreu em 1899.

\footnotetext{
${ }^{35}$ Ver a imagem em:

http://catalogo.bnportugal.pt/ipac20/ipac.jsp?session=1E53578F5520R.4948\&profile=bn\&source= !bnp $\&$ view $=$ subscriptionsummary \&uri $=$ full $=3100024 \sim$ !670203 $\div 4 \&$ ri $=1 \&$ aspect $=$ subtab $93 \&$ menu $=$ tab20\&ip $\mathrm{p}=20 \& \mathrm{spp}=20 \&$ staffonly $=\&$ term $=$ sao + luis \&index $=. \mathrm{GW} \&$ uindex $=\&$ aspect $=$ subtab $93 \& \mathrm{menu}=$ search $\& \mathrm{ri}=$ 1

${ }^{36}$ O Álbum do Maranhão de 1908, encontra-se sob a guarda do Museu Histórico e Artístico do Maranhão e as autoras tiveram acesso ao original.

${ }^{37}$ Bogéa, K. S.; Ribeiro, E. S.; Brito, S. R. S.de, 2008: 81.
}

41 Regiane A. Caire Silva y Marília M. França Sousa. A C de J em São Luís... 31-50. 


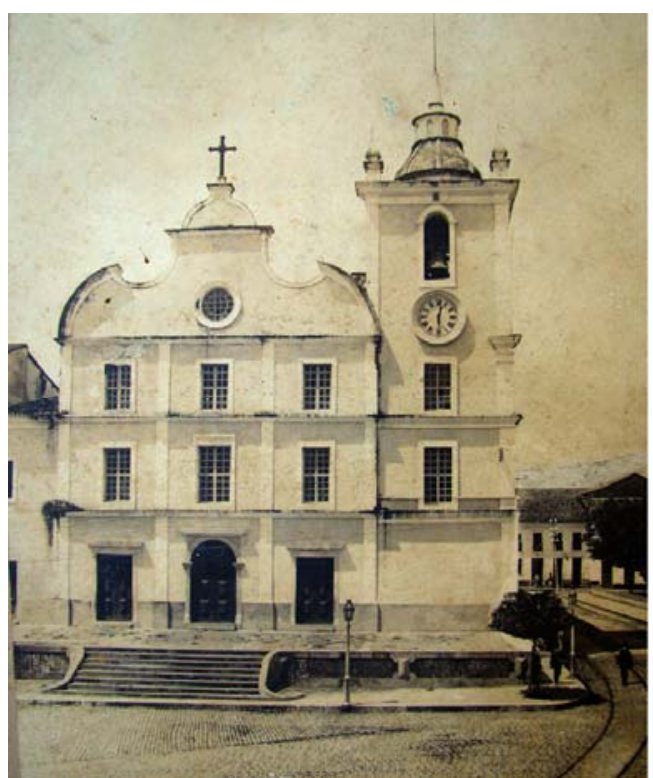

Fig. 2 Catedral da Sé - 1908 Fotografia de Gaudêncio Cunha ${ }^{38}$

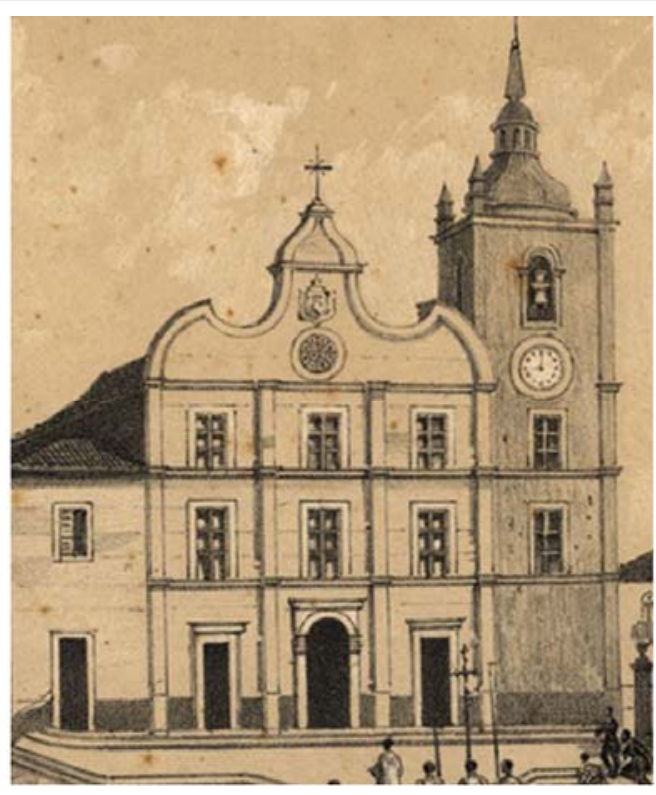

Catedral da Sé - 1856 Litografia

O mesmo não ocorreu com o Palácio Episcopal. Na litografia a fachada encontrase de acordo com o estilo colonial da igreja, no entanto a fotografia de Gaudêncio relata a descaracterização arquitetônica com ornamentação neoclássica, distanciando radicalmente da característica colonial do templo.

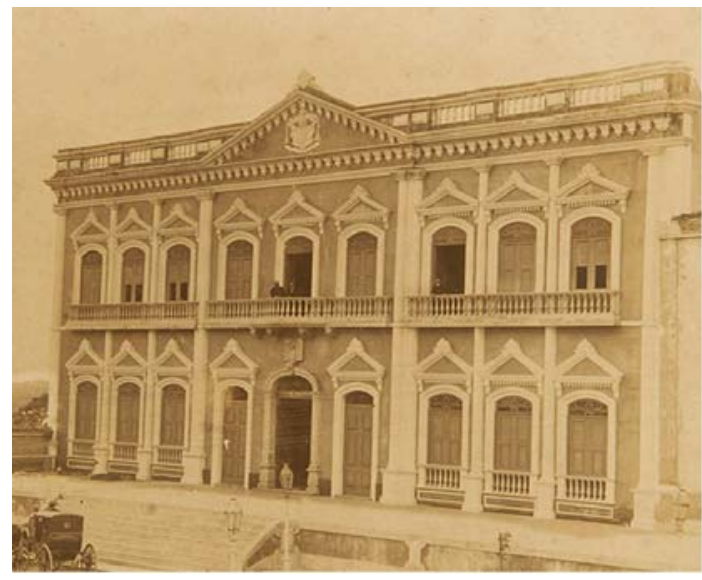

Fig. 3 Palácio Episcopal - 1908 Fotografia de Gaudêncio Cunha ${ }^{39}$

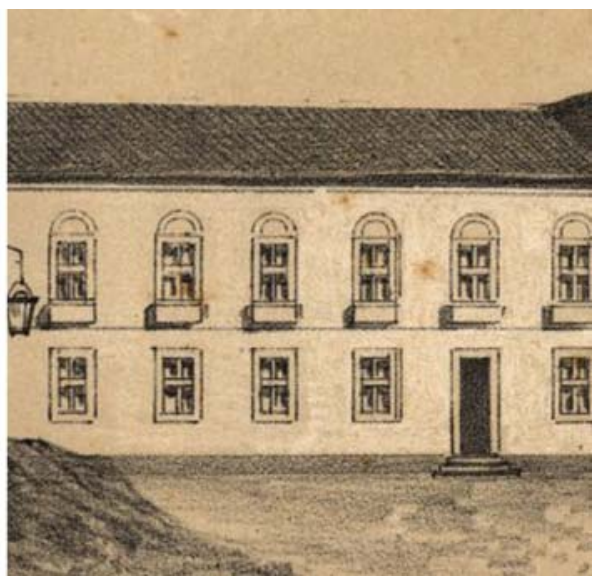

Palácio Episcopal - 1856 Litografia

Em meados no século XX, transformações drásticas também marcaram a fachada da Igreja da Sé.

\footnotetext{
${ }^{38}$ Reprodução a partir do original feito pelas autoras. Fonte: Museu Histórico e Artístico do Maranhão MHAM

${ }^{39}$ Reprodução a partir do original feito pelas autoras. Fonte: Museu Histórico e Artístico do Maranhão MHAM
}

42 Regiane A. Caire Silva y Marília M. França Sousa. A C de J em São Luís... 31-50. 


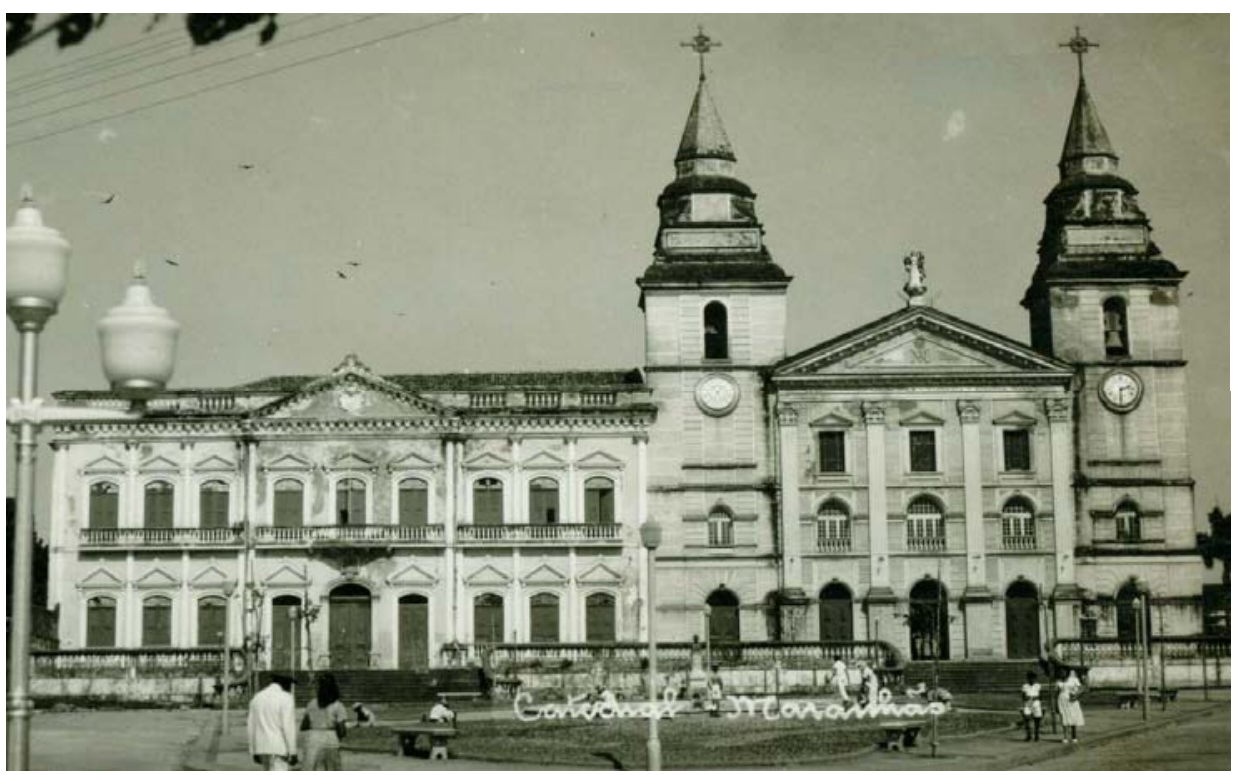

Fig. 4 Vista da Catedral da Sé e Palácio Episcopal. Início do séc.XX. Fonte: Biblioteca Digital do IBGE, s.d $\mathrm{d}^{40}$

Nesta imagem (Fig. 4) observa-se: a catedral com duas torres, frontão completamente modificado, desaparecimento do óculo, inserção de vitrais e a "modernização" de estilo, do colonial para o neoclássico; uma total distorção do que era o templo original erguido pelos jesuítas.

A segunda torre foi construída por volta de 1922 para ligar o Palácio, antigo Colégio da Luz, à igreja. A reforma de 1922 se deu "por conta das comemorações do centenário da independência do Brasil, quando se realizaram grandes obras públicas no Maranhão"41. As obras constituídas nesse ano certamente contribuíram para as intervenções mais graves do ponto de vista técnico, histórico e estético.

A razão para tais intervenções indica a necessidade de acompanhar a "modernização", que também ocorreram em outras cidades brasileiras, portando-se como vitrine do crescimento industrial e, consequentemente, o registro do progresso justificado nas reformas das edificações no início do século XX.

O gosto da época por um estilo arquitetônico eclético com elementos do neoclássico é claramente notado na decoração da fachada, como, por exemplo, as pseudos colunas, frontões triangulares, simetria, decoração caracterizada por elementos estruturais com formas clássicas.

Conforme D. Francisco de Paula e Silva o Palácio Episcopal teve sua fachada modificada para o estilo neoclássico em decorrência da reforma realizada na gestão, entre os anos de 1901 a 1905, do bispo D. Antônio Xisto Albano, o que lhe custou várias críticas forçando-o a pedir renuncia em $1905 .{ }^{42}$

\footnotetext{
${ }^{40}$ Ver imagem: http://biblioteca.ibge.gov.br/index.php/biblioteca-catalogo?view=detalhes\&id=49862

${ }^{41}$ Bogéa, K. S.; Ribeiro, E. S.; Brito, S. R. S. de, 2008: 84.

${ }^{42}$ Paula e Silva, F. de, 1922: 408-409.
}

43 Regiane A. Caire Silva y Marília M. França Sousa. A C de J em São Luís... 31-50. 
Portanto, podemos acreditar que a igreja Nossa Senhora da Vitória acompanhou a "modernização" que o Palácio Episcopal obteve anteriormente em busca de uma unidade de conjunto, confirmada, três anos depois, na fotografia de Gaudêncio Cunha em 1908.

A intervenção não se limitou apenas externamente propagou-se também para o interior do templo (Fig.5). Observou-se diversas modificações internas em muitos elementos decorativos, porém, o recorte deste trabalho se ateve ao retábulo e ao forro da capela-mor.

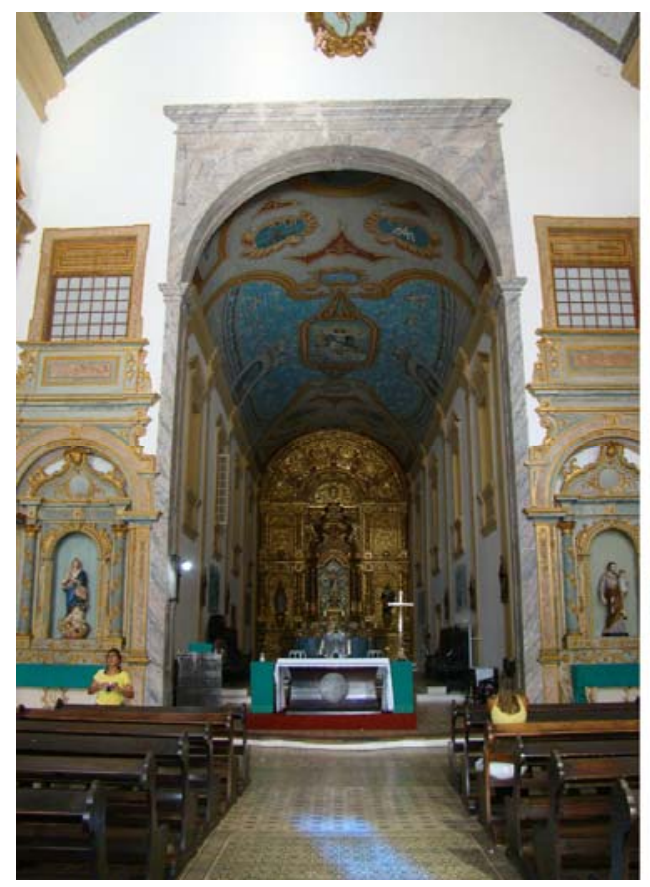

Fig. 5 Interior da Catedral da Sé Foto das autoras - 2015

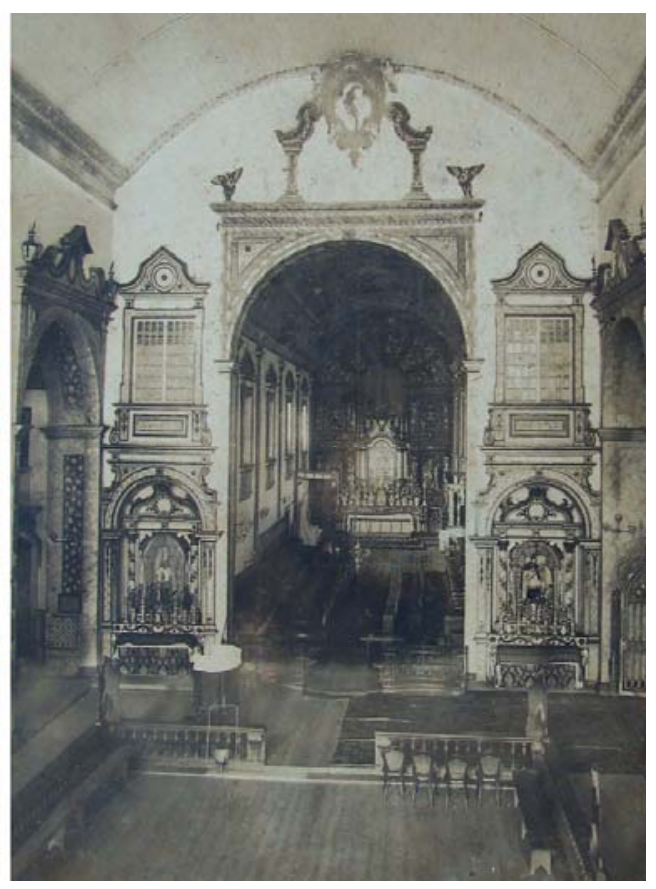

Interior da Catedral da Sé. Gaudêncio Cunha 1908

Encontramos escassa informação a respeito das intervenções ocorridas no interior da igreja, entretanto, no livro de D. Francisco de Paula e Silva que narra à trajetória da Arquidiocese do Maranhão, próximo ao final das suas 483 páginas, um laudo sobre o restauro realizado no período de 1883 a 1886 é preciso e revelador. Uma comissão nomeada pelo bispo D. Antônio Candido de Alvarenga, que atuou no bispado de 1876 a 1899, apresenta um laudo onde descreve problemas de várias ordens, o que demonstra a necessidade urgente de intervenções, segundo o relatório, a situação geral da igreja era muito precária.

[...] procurou esta comissão operários peritos para fazê-las, procedendo logo a um exame e vistoria de todo o edifício da Egreja Cathedral e suas muitas dependências. Desse exame resultou verificar-se que todo o tecto da nave da capella-mór do templo e da capela de N.S. da Boa Morte e da grande sacristia dos Pontíficaes, sala da lavanda, do alpendre, latrinas e consistórios estavam 
completamente apodrecidos e em tal estado que, só a Divina Providencia obstou que sobre os fiéis e Corporação Capitular abatessem os arcos do templo. ${ }^{43}$

Nota-se os cuidados emergenciais que a igreja necessitava e a preocupação em relatar que os operários que trabalhariam na obra seriam peritos. Sobre o retábulo e outras peças de madeira diz "estavam em grande parte deteriorados, carecendo alguns de novas peças". Descreve que o retábulo do altar-mor havia pintura e redouramentos,

os retábulos do altar-mor e o throno da Boa Morte e os 6 da nave, além de estarem pintados com gosto, acham-se quase na sua totalidade redourados, aproveitando-se apenas o ouro antigo nas peças que não foram substituídas e nas em que se conservava perfeito. ${ }^{44}$

Sobre a pintura do forro da capela da N.S. da Boa Morte que "poude felizmente ser bem restaurada", não existe mais e não temos como constatar de como era, pois não há informações até este momento da pesquisa. Mais adiante no laudo, faz-se uma revelação importante em relação à pintura do forro da capela-mor.

O forro da nave que é abobadado e tem 135 palmos de comprimento é todo novo, tendo soffrido grandes reparos os da capela-mor, cujas novas cambotas foram collocadas junto ás antigas, afim de serem aproveitadas, como o foi a magnífica pintura que o orna, original do tempo dos Revmos. Padres da Companhia de Jesus. ${ }^{45}$

Nesta informação fica claro que o forro da nave central no final do século XIX foi totalmente trocado, por este motivo não existe nenhum registro de pintura, como pode mostrar a fotografia da parte interna da igreja registrada por Gaudêncio Cunha em 1908. Por outro lado, revela a existência de uma pintura no forro na capela-mor pertencente aos jesuítas, "uma magnífica pintura". Na Crônica do padre Filipe Bettendorff, também reforça que a pintura jesuítica existiu, relatando ter sido executada pelo irmão Marcos Vieira e preenchia toda a capela, o que somada à imagem fotográfica de Gaudêncio (Fig. 6) nos dá a ideia de ter sido uma pintura de significativa magnitude:

Fez-lhe uma capela-mor forrada de todas as partes com suas tribunas e grades, pintadas por ambas as bandas; pintou o irmão Marcos Vieira, por invenção sua, a capela toda; pôs-se-lhe o altar com o sacrário e a Senhora posta em cima, em seu lugar, depois de rebocada e branqueada toda a obra... ${ }^{46}$

Observando atentamente a fotografia de Gaudêncio (Fig. 6), pode-se constatar uma imagem diferente da existente hoje, conforme detalhe ampliado a seguir.

\footnotetext{
${ }^{43}$ Paula e Silva, F. de, 1922: 332.

${ }^{44}$ Ibid.:332.

${ }^{45}$ Ibid.: 333 .

${ }^{46}$ Bettendorff, J. F.,2010: 586.
} 


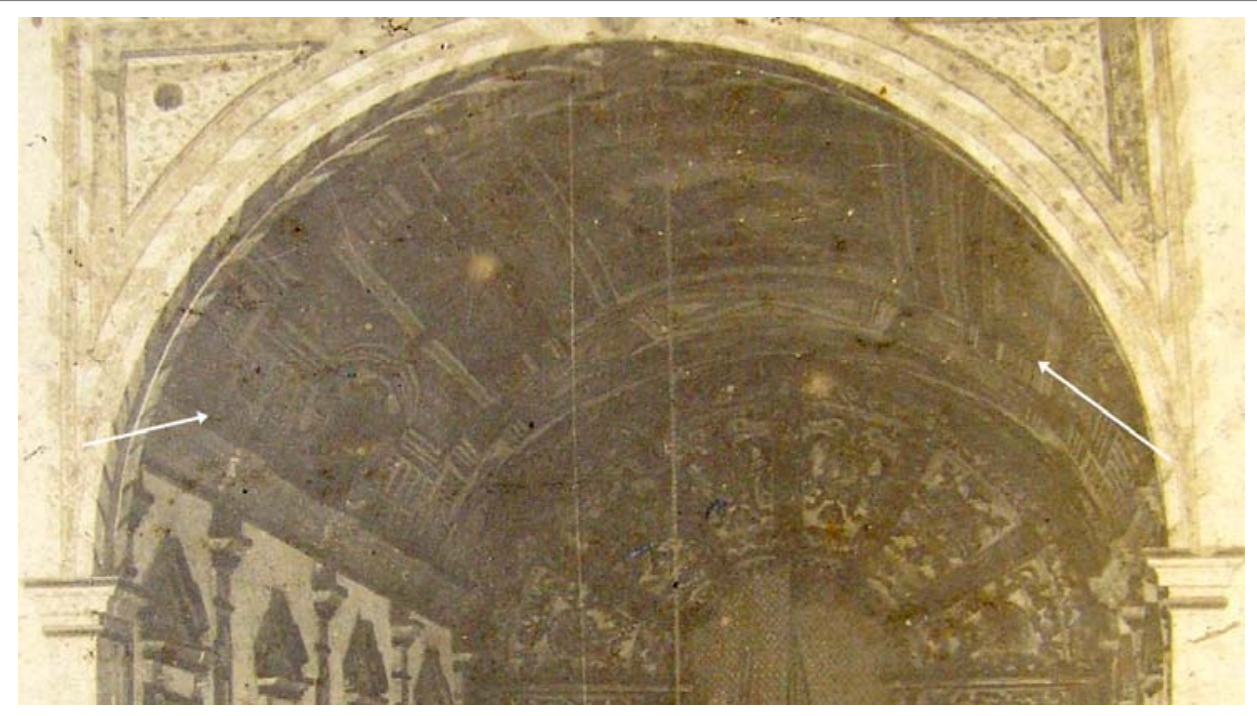

Fig.6 Foto de Gaudêncio Cunha 1908 - Detalhe - Forro da capela-mor ${ }^{47}$

Apesar da falta de nitidez a ampliação mostra que existia uma pintura anterior a atual, percebe-se que a imagem acompanha a cúpula do forro e está repleta de elementos ornamentais, dando ao conjunto uma unidade harmoniosa e plena. Inclusive com o retábulo dourado do século XVII ao fundo do espaço, que traz sobriedade, imponência e riqueza características tão bem conquistadas pelos trabalhos realizados pelos jesuítas. Não foram encontrados nesta pesquisa relatos que descrevam em detalhes como ocorria o funcionamento da produção artística no interior das oficinas do Colégio da Luz, especialmente no que se refere à pintura.

A pintura encontrada nos dias atuais (Fig. 7) foi feita por João de Deus (1896-?). Analisando-a brevemente, observa-se o uso de cores claras com predomínio do azul, amarelo e branco; ornamentação repleta de vazios; pouco uso da perspectiva, bem ao gosto da proposta artística do inicio do século XX; posicionamento da imagem central da figura da Assunção de Nossa Senhora perpendicular ao arco.

Conforme dados escritos no arco da capela-mor o artista teria executado duas pinturas no forro da igreja: a primeira de 1927 na capela-mor e a segunda de 1956 na nave central onde acrescenta outros elementos ornamentais.

\footnotetext{
${ }^{47}$ Reprodução fotográfica de original feita pelas autoras a partir de fotos de Gaudêncio Cunha, 1908. Detalhe que mostra a pintura original realizada pelos jesuítas. Fonte: Museu Histórico e Artístico do Maranhão - MHAM
} 


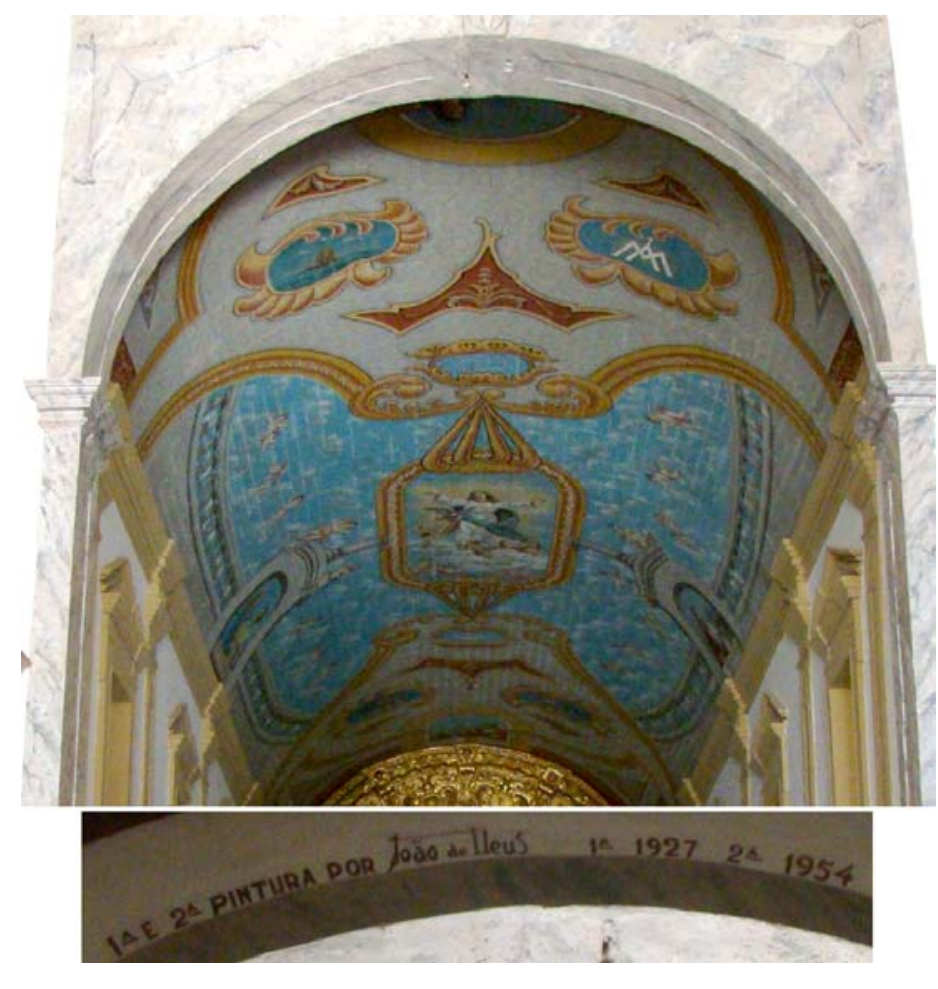

Fig. 7 Interior da igreja.

Detalhe do forro da capela-mor com pintura de João de Deus.

Inscrição das datas das pinturas realizadas pelo artista.

Foto das autoras-2015

A imagem registrada por Gaudêncio Cunha (Fig. 6) prova a existência da pintura no forro da capela-mor realizada pelos jesuítas confirmada por Dom Francisco de Paula e Silva, "a magnífica pintura que o orna, original do tempo dos Revmos. Padres da Companhia de Jesus" e também por Pe. Filipe Bettendorff.

Levantamos a hipótese que a obra jesuítica poderia estar sob a pintura de João de Deus, caso fosse confirmada, seria talvez, a única existente em São Luís. Entretanto, no Inventário Nacional de Bens Móveis e Integrados do Maranhão ${ }^{48}$ relata que o forro da nave central, bem como, o da capela-mor "após passarem por intervenções no século XVIII e XIX, foram totalmente retirados em reforma ocorrida no início do XX", e ainda completa que receberam uma nova pintura em 1927 por artista maranhense, João Batista de Deus. O registro de Gaudêncio Cunha é a única prova visual, até o momento, que revela ter existido uma pintura jesuítica até 1908 .

Quanto ao retábulo, segundo o laudo da empresa de restauro feito em 1993/94 ${ }^{49}$, ouve intervenção de conservação física e reintegração cromática anterior, em 1959, realizada pelo restaurador Edson Motta (1910-1981). O diagnóstico descrito por Motta aponta duas alterações "as reversíveis foram às alterações cromáticas como o recobrimento de várias áreas douradas por pintura azul; e as irreversíveis foram as inserções físicas de substituição, como entablamento e mesa rococós, e o nicho neoclássico do camarim". Sobre o tom azul aplicado com tinta óleo sobre o douramento,

\footnotetext{
${ }^{48}$ Brito, Stella.R.S., 2000: 56.

${ }^{49}$ Consultado no IPHAN do Maranhão.
}

47 Regiane A. Caire Silva y Marília M. França Sousa. A C de J em São Luís... 31-50. 
a equipe de Edson Motta decidiu em removê-lo "pois intervia de maneira incisiva na leitura estilística do retábulo, inclusive por cobrir a talha maneirista, tradicionalmente dourada, falseando a sua compreensão e enquadramento artístico".

$\mathrm{Na}$ observação de Bomfim $^{50}$ sobre o restauro executado em 1959 diz: "o Patrimônio não o restaurou, apenas, ressuscitou-o", continua, "canta a fé de outrora no ouro da generosidade dos que como tal o talharam, em louvor da Virgem da Luz, que sempre a Senhora de toda Vitória".

O laudo posterior de 1993/94, aponta que, provavelmente, a tonalidade azul deve ter sido colocada quando a inserção dos elementos rococós em data posterior, e "o douramento encontrado sob o azul o retorna às condições cromáticas condizentes com o estilo do entalhe, permitindo a segurança ao datar o retábulo como obra da segunda metade do século XVII". Assim, justificou-se a remoção da tinta azul no restauro.

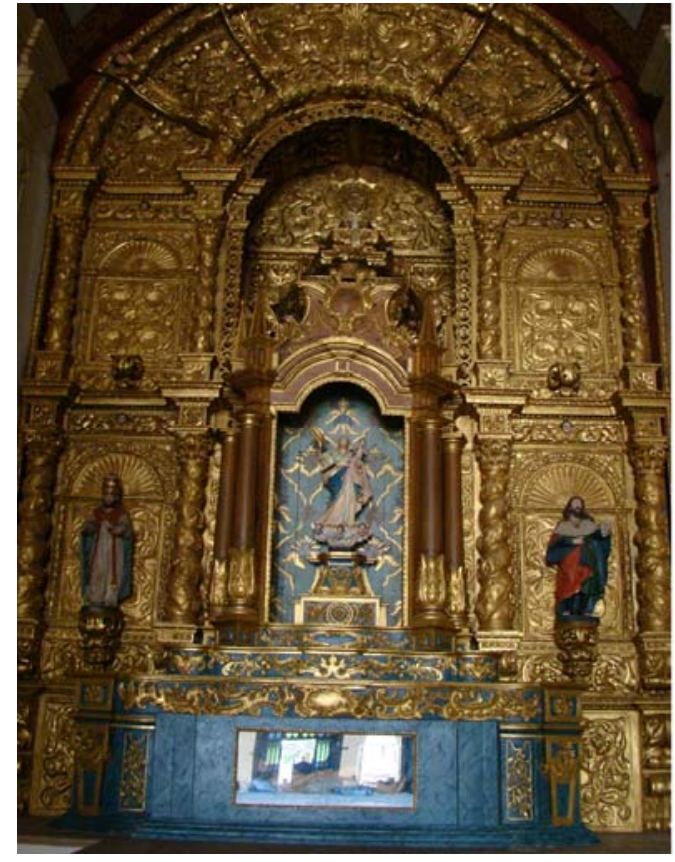

Fig. 8 Retábulo em 2015 após sucessivos processos de restauro. Foto das autoras

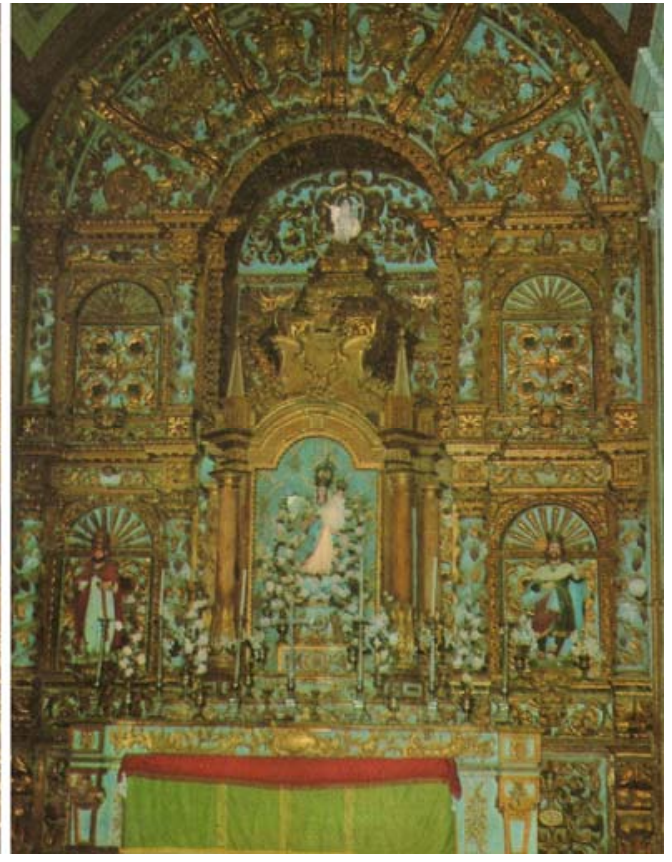

Retábulo antes do restauro de 1993 Fonte: Museu da Memória Áudio Visual do Maranhão MAVAM

Nota-se (Fig. 8) que o retábulo retornou com o restauro ao seu dourado quase pleno evidenciando o estilo maneirista melhorando, significativamente, o seu aspecto e importância como obra jesuítica do período XVII. Não foi possível remover toda a tinta azul devido ao enxerto irreversível do nicho, mesa e entablamento onde houve perda do elemento anterior.

O laudo sobre o restauro do retábulo termina com a seguinte conclusão:

\footnotetext{
${ }^{50}$ BOMFIM, Antonio Bezerra. Altar Mor da Igreja de Nossa senhora da Vitoria. Maranhão: Departamento de Cultura do Estado, 1968, p.2.
} 
Temos agora um Retábulo maneirista, no risco, formas e tratamento cromático, com douramento integral; enxertado por entablamento e mesas rococós, com seu tom azul cobalto; e nicho neoclássico, com seu tom salmão, de imitação de pedra mármore. Esta definição, permite a leitura quase que integral do retábulo maneirista, e de sua incrustações formais e cromáticas posteriores, numa convivência harmoniosa e historicamente elucidativa. ${ }^{51}$

Retornando a questão do tombamento do retábulo, Lúcio Costa afirma que essa ação poderia retratar o dano causado à memória dos jesuítas que "foi profanada". Deixa-nos a dúvida quando cita a data de 1927: "a limitação do tombamento ao retábulo com as respectivas imagens - peças jesuítas contemporânea do antigo colégio pareceu-me desejável como desagravo à memória dos padres cuja obra foi profanada, em $1927^{, 52}$. Coincidência ou não, esta data é exatamente o ano em que João de Deus fez a primeira pintura na capela-mor, talvez este artista tenha contribuído, também, na inserção da pintura azul celeste sobre o douramento do retábulo nas várias intervenções ocorridas devida a comemoração do Centenário da República em 1922.

Deve-se frisar que as ações de preservação e conservação no Brasil começaram a ser discutidas e normatizadas com o Serviço do Patrimônio Histórico e Artístico Nacional SPHAN, projeto idealizado pelo escritor Mário de Andrade, instituído por decreto-lei nº 25 de 30 de novembro de 1937.

\section{Considerações finais}

A pesquisa surgiu com o objetivo de identificar intervenções realizadas na Catedral Nossa Senhora da Vitória - denominada à época dos jesuítas de Igreja Nossa Senhora da Luz no período entre os séculos XVIII e XX. No decorrer do levantamento bibliográfico, documental e da visitação ao templo, não tínhamos a dimensão de quais hipóteses seriam levantadas, de quais histórias seriam reveladas. Investigar a trajetória da Companhia de Jesus, desde sua chegada à terras maranhenses, acompanhar a tentativa de estabelecimento da ordem em meio às sucessivas expulsões; foi resgatar um pequeno pedaço da história do Maranhão em seus primórdios, história esta, que clama por ser a cada dia redescoberta. $\mathrm{O}$ trabalho realizado apontou o caminho para identificar e divulgar a importância da existência de uma pintura jesuítica no forro da capela-mor anterior à encontrada nos dias atuais. Bem como, o trabalho realizado no interior da oficina de entalhe, com destaque para o retábulo da capela-mor, patrimônio não apenas maranhense, mas brasileiro.

Desde o primeiro momento de visita ao templo pode-se notar um desconforto visual em relação ao ecletismo encontrado. $\mathrm{O}$ descompasso entre o majestoso retábulo maneirista dourado com as pinturas dos forros da capela-mor e da nave central por apresentarem estilos diversos, bem como, às alterações na fachada da igreja e do palácio. A partir destas observações a pesquisa iniciou-se, também, com o objetivo de compreender e esclarecer as diversas intervenções realizadas no projeto do Pe. Jesuíta Filipe Bettendorff ao longo das várias gestões administrativas da diocese a qual a catedral pertenceu.

\footnotetext{
${ }^{51}$ Laudo do Restauro do Retábulo da Igreja Nossa Senhora da Vitória. Empresa Itapoá: Salvador, 1993.

${ }^{52}$ Costa, L., 2004:142
}

49 Regiane A. Caire Silva y Marília M. França Sousa. A C de J em São Luís... 31-50. 
Com tantas intervenções ocorridas nos edifícios e no interior da igreja, restounos apenas o retábulo do século XVII da capela-mor da igreja Nossa Senhora da Vitória que manteve, em grande parte, a originalidade artística da Companhia de Jesus e nos mostra como testemunho a exímia habilidade exercida pelos artífices indígenas e jesuítas.

Procurou-se estabelecer o diálogo entre passado e presente, para compreender de que forma essas intervenções foram sendo realizadas. Constatou-se, que o processo de modernização sem um projeto consciente reflete e altera de forma significativa o patrimônio em diferentes nuances de caráter tanto histórico como estético.

\section{Bibliografía}

Bettendorff, João Filipe (2010), Crônica da Missão dos padres da Companhia e Jesus no Estado do Maranhão, Brasília: Senado Federal, Conselho Editorial.

Brito, Stella.R.S. et al.,(2000), Inventário Nacional de Bens Móveis e Integrados: a Experiência do Maranhão, São Luís: IPHAN $/ 3^{\text {a }}$ SR.

Bógea, Kátia; Brito, Stela; Ribeiro, Emanuela (2002), Olhos da alma: Escola maranhense de imaginária, São Luís do Maranhão: IPHAN.

Bogéa, Kátia Santos; Ribeiro, Emanuela Sousa; Brito, Stella Regina Soares de (2008), Arquitetura e arte religiosa no Maranhão, São Luís: $3^{\text {a }}$ Superintendência regional/IPHAN.

Bomfim, Antonio Bezerra (1968), Altar Mor da Igreja de Nossa senhora da Vitoria, Maranhão: Departamento de Cultura do Estado.

Costa, Lúcio (2004), Documentos de trabalho, Org., Pessoa, José, Rio de Janeiro: IPHAN.

Leite, Serafim (1953), Artes e Ofícios dos Jesuítas no Brasil: 1549-1760, Lisboa/Rio de Janeiro: Broteria Livros de Portugal.

Lima, Carlos de; Meireles, Mário; Bogéa, Kátia Santos (2002), Palácio arquiepiscopal: 100 anos de história,São Luís: Editora Clara.

Paula e Silva, Francisco de (1922), Apontamentos para a História Eclesiástica do Maranhão, Bahia: Typographia de São Francisco.

Pacheco, D. Felipe Conduru (1969), História Eclesiástica do Maranhão, São Luís: Departamento de Cultura do Estado.

Silva Filho, Olavo Pereira da (1998), Arquitetura Luso-Brasileira no Maranhão, Belo Horizonte: Formato.

Toledo, Benedito Lima de (1983), "Do século XVI ao início do século XIX: maneirismo, barroco e rococó". En Zanini, Walter (Org.), História geral da arte no Brasil. São Paulo: Instituto Walter Moreira Sales, 177. 